\title{
The Relationship among Sport Media Involvement Experience, Sport Participation, Sport Values in Adolescent: Structural equation modelling
}

\author{
Seung-Man Lee ${ }^{1}$ \\ Global Cyber University \\ lsm14pe@gmail.com
}

\begin{abstract}
This study investigated how the relation of sport media involvement experience, sport participation and sport values utilizing structural equation modelling. Survey responses of 659 adolescent were analyzed by SPSS and AMOS 18.0. SMIE was found to positively effect sport participation, and sport participation positively affected sport values. But SMIE had no direct effect on sport values. In conclusion, SMIE was found to significantly affect the establishment of adolescents' sport values through sport participation.
\end{abstract}

Keywords: Sport Media Involvement Experience, Sport Participation, Sport Values, Adolescent.

\section{Introduction}

In the Fourth Industrial Revolution, people can not only get any information they want, anytime, anywhere, but also communicate with others across time and space. Alongside this trend, however, it is highly likely that people will become more individualistic, to the extent that people-to-people exchanges might decrease. Thus, it is expected that only relationships, not beings, will remain in interpersonal relationships, and communication will be increasingly important among humans and organizations as well as between humans and organizations; sports have been suggested as a solution for this problem (Yoo, Jun, \& Choi, 2017) [3]. Lee (2015)[4] defines "life skills" as learning various problem-solving methods from experiences acquired while living with other people and stresses the importance of sport education during adolescence as the best method to learn life skills in advance. Meanwhile, In adolescence, individuals develop various values due to the influence of their surrounding environment. Sport values are one of the various attitude domains stemming from attitudes towards sports or impressions of sports and serve as a determinant of sport activities over an individual's lifetime (Leonard, 1980 [15]). Thus, sport values derive from organic relationships between many different environments and should be examined in relation to such relationships. Significant for understanding the specific relationships between various predictors influencing adolescents' sport values and provides empirical evidence for the role of sport media as an agent of socialization in the sport socialization process and in the formation of sport values. This study aims to develop a model wherein adolescents' sport media involvement experience is related to sport participation, which ultimately forms their sport values, and to test the model

Article history:

Received (March 15, 2019), Review Result (June 14, 2019), Accepted (July 20, 2019) 
empirically. The primary purpose of this study was to investigate the Structural relationship between adolescents' Sport Media Involvement Experience (SMIE), Sport Participation and their Sport Values.

\section{Research Methods}

\subsection{Participants}

This study used convenience sampling, a non-probability sampling method which samples subjects who can be accessed at a time and place convenient to the researchers(Sung, 2014 [14]). To achieve its goal, this study was divided into a preliminary survey and a main survey. The preliminary survey examined 208 adolescents living in Seoul, while the main survey examined 451 adolescents living in Republic of Korea. <Table 1> shows the specific

Table 1. General characteristics of participants.

\begin{tabular}{|c|c|c|c|c|c|}
\hline \multirow[b]{2}{*}{ Variable } & \multirow[b]{2}{*}{ Category } & \multicolumn{2}{|c|}{ Preliminary survey } & \multicolumn{2}{|c|}{ Main survey } \\
\hline & & $\begin{array}{l}\text { No. of cases } \\
\text { (adolescents) }\end{array}$ & $\begin{array}{l}\text { Percentage } \\
\text { (\%) }\end{array}$ & $\begin{array}{l}\text { No. of cases } \\
\text { (adolescents) }\end{array}$ & $\begin{array}{c}\text { Percentage } \\
\text { (\%) }\end{array}$ \\
\hline \multirow{2}{*}{ Gender } & Male student & 103 & 49.5 & 218 & 48.3 \\
\hline & Female student & 105 & 50.5 & 233 & 51.7 \\
\hline \multirow{3}{*}{$\begin{array}{c}\text { School } \\
\text { Level }\end{array}$} & Middle school & 110 & 52.9 & 232 & 51.4 \\
\hline & High school & 98 & 47.1 & 219 & 48.6 \\
\hline & Total & 208 & 100 & 451 & 100 \\
\hline
\end{tabular}

\subsection{Measurement Tools}

This study employed a questionnaire survey using items that were deemed fit for its purposes from tools used in previous studies whose reliability and validity had been tested. A preliminary survey was conducted to determine the tool's reliability and validity, and based on the results obtained in the preliminary survey, the main survey was conducted to examine the relationship between variables. Below is the description of the questionnaire used as a result of the preliminary survey: the questionnaire items measuring sport media involvement experience in this study followed the questionnaire applied by Chung (2006) [7] concerning sport media involvement and that used by Lee, Lee \& Kim (2013) [2] based on the involvement-level scale developed by Kim (2010)[6]. It included 10 sub-factors: interest level, importance, relevance, choice, necessity, interest, recommendation, data collection, significance, and difference level. The questionnaire items measuring sport participation were drawn from Lee, Lee \& Kim (2013) [2], based on the sport participation classification model of Snyder \& Spreitzer (1973) [1]. There were three sub-factors, including behavioral, cognitive, and affective participation. Specifically, the sport participation questionnaire consisted of twelve items: three concerning cognitive participation, six concerning behavioral participation, and three concerning affective participation. As for the sport values questionnaire items, this study addressed six value factors, excluding intellectual and religious values, presented in the sport values classification models of Evarett (1962)[8] and Allport, Vernon, \& Lindsey (1960) [9] and the questionnaires used by Jung (2008) [10]. There were 17 items in total: three concerning social values, three concerning entertainment values, three concerning for aesthetic values, four concerning character values, 
and four concerning physical values. The questionnaire used a Likert scale in which the participants responded on 1-5-point scale.

\subsection{Reliability test}

The present study used Cronbach's $\alpha$ to test for the internal reliability of items in the questionnaire. Cronbach's $\alpha$ ranges from 0 to 1 , and it is considered reliable in normal cases when $\alpha$ is .8 or higher (Sung, 2014 [14]). Accordingly, items were removed when their $\alpha$ was less than .8 , or when the overall Cronbach's $\alpha$ without the item was higher than it was with the item. Based on the above, this study removed one social-values item and one physical-values item.3.4 Potential of Interaction Spaces between Generations of Complex Facilities for Old and Youth

\section{4 Validity test}

This study used variables whose logical evidence had been examined previously and thus had sufficient evidence to form a hypothesis, only a confirmatory factor analysis was performed. In this study' s confirmatory factor analysis, CFI $>.9$ and RMSEA $<.1$, which are free from the sample' s characteristics, were accepted as indicating goodness of fit (Hong, 2000 [5]). However, CFI was found to be .901 and RMSEA was .105. Since these goodness of fit indices were found to be below the baseline, the model needed to be revised in order that the baseline might be met. This study employed a method that first removed items with considerable cross loading among modification indices (MI), referred to as SMC, and then continued removing additional items. As a result, two observable variables (significance and entertainment value) were removed. A confirmatory factor analysis for goodness of fit of the revised model generated through this process showed that CFI was .928 and RMSEA was .093. Accordingly, the model' s goodness of fit indices were deemed acceptable. Next, convergent validity was tested. In determining convergent validity, all variables' factor loading should range from .5 to .95 while the critical ratio (CR) should be 1.965 or higher, the average variance extracted (AVE) should be higher than .5, or the concept reliability should be higher than .7 throughout (Woo, 2015 [11]). The present study used all three methods to test convergent validity. All factors' factor loading ranged from .667 to .910 and the CR was 1.965 or higher. In addition, concept reliability ranged from .988 to .993 . Finally, the AVE ranged from .938 to .966 . As the variables satisfied these three test requirements, they were found to possess convergent validity. Next, discriminant validity was tested. This study used the AVE, the most rigorous method to obtain discriminant validity. Specifically, the squared coefficient of the most highly correlated variables - "sport media involvement experience (b)" and “sport participation (c)" was .570, which was lower than the AVE of "sport media involvement experience" (.938) and "sport participation" (.966). Hence, discriminant validity was confirmed.

\subsection{Data Processing Method}

This study excluded from analysis data that were deemed unreliable due to missing or incomplete responses to questionnaire items, input analyzable and useful data, and used SPSS and AMOS 18.0 software programs for data analysis. Analysis details and methods are described below. This study excluded from analysis data that were deemed unreliable due to missing or incomplete responses to questionnaire items, input analyzable and useful data, and used SPSS and AMOS 18.0 software programs for data analysis. Analysis details and methods are described below. Cronbach's $\alpha$ was used to test the scale's reliability and a confirmatory 
factor analysis was performed to test validity, after which convergent validity and discriminant validity were tested. Next, a descriptive statistical analysis was performed, followed by a path analysis to test the relationship between variables.

\section{Results}

\subsection{Descriptive Statistics Analysis}

To examine the descriptive statistics of variables used in analysis, this study analyzed descriptive statistics for the total score and sub-factors of sport media involvement experience, sport participation, and sport values. Means ranged from 2.37 to 4.17, and standard deviations from .73 to 1.14. The skewness and kurtosis values that could indicate a structural equation' s stationarity were also examined. More specifically, skewness concerns whether data are symmetrical left and right and maintain normality, while kurtosis indicates whether scores are concentrated in the middle or at the end of a normal distribution curve. As for thresholds to violate univariate normality, skewness $< \pm 3.0$ (West, Finch, \& Curran, 1995 [13]) and kurtosis $< \pm 10.0$ are considered to satisfy the requirements of a normal distribution (Kline, 2011 [12]). The results showed that absolute skewness values ranged from .02 to 1.01, and absolute kurtosis values ranged from .01 to 1.59 . Since these results satisfied the structural equation' $\mathrm{s}$ stationarity, estimating an unknown quantity using the maximum likelihood method was deemed to not have an effect on the results and thus achieved goodness of fit in the structural equation model test.

\section{2. path analysis}

The direct effect size and test results of the final model (competition model) are provided in $<$ Table 2>. First, the effect of sport media involvement experience (A) on sport participation (B) showed that the path coefficient was $.799(t=14.221)$ and significant. Second, the effect of sport media involvement experience (A) on sport values (C) showed that the path coefficient was $.008(\mathrm{t}=.111)$ and not significant. Third, the effect of sport participation (B) on sport values $(\mathrm{C})$ showed that the path coefficient was $.762(\mathrm{t}=9.303)$ and significant.

Table 2. Results of the hypothesis model test.

\begin{tabular}{cccccccc}
\hline & Path & & $\begin{array}{c}\text { Standardized } \\
\text { regression weight }\end{array}$ & $\begin{array}{c}\text { Regressio } \\
\text { n weight }\end{array}$ & SE & CR & $p$ \\
\hline $\mathrm{A}$ & $\rightarrow$ & $\mathrm{B}$ & .799 & .591 & .042 & 14.221 & $.000^{* * *}$ \\
\hline $\mathrm{A}$ & $\rightarrow$ & $\mathrm{C}$ & .008 & .006 & .054 & .111 & .912 \\
\hline $\mathrm{B}$ & $\rightarrow$ & $\mathrm{C}$ & .762 & .794 & .085 & 9.303 & $.0000^{* * *}$ \\
\hline
\end{tabular}

\section{Discussion}

Based on the relationship in the relationship sport media involvement experience, sport participation, sport values, the following discussion is presented in comparison with previous studies. These results show that adolescents' sport media involvement experience may serve as a motivator that directly leads to sport participation, encouraging them to participate in sports and thereby form proper sport values. This may suggest that when they are involved in sport media and participate in sports, they can establish essential and positive values in determining 
various experiences and values that might occur from directly participating in sports. In summary, the results of this study suggest that more sport media involvement experience is likely to lead to increased sport participation, and more sport participation results in the formation of sport values. It could be possible, however, that when adolescents are involved in sport media but do not directly participate in sports, its effect on establishing sport values would be lower. It would be difficult for adolescents to establish the values that can be observed and experienced when directly participating in sports on their own, without participating in sports. Hence, sport media involvement experience and sport participation are important given that higher sport media involvement experience works as an agent of socialization in the sport socialization process and motivates adolescents to participate in sports, through which they can form ideal sport values. Overall, adolescents' sport participation stemming from their sport media involvement experience helps them to form proper sport values. Further, since it is possible that higher sport values indicate more interest in sports, sport values could have an effect on sport participation. The results suggest the following implications. Sport media is one of significant others in the sport socialization process that can lead to participation in sports. Therefore, since sport participation is an important variable that can help to establish sport values, enhancing sport participation would help adolescents to form better sport values. This suggests that developing various programs using sport media and including strategies that increase sport participation when applying adolescent-focused programs would help adolescents to better establish sport values.

\section{Conclusions}

The purposes of this study were to test what effect adolescents' sport media involvement experience has on sport participation and sport values. To achieve these aims, a preliminary survey and a main survey were conducted. According to the results, first, sport media involvement experience had a positive effect on sport participation. Second, sport media involvement experience had no direct effect on sport values. Third, sport participation had a positive effect on sport values. Based on the above, the study concludes that adolescents' sport media involvement experience had an indirect effect on sport values through the mediation of sport participation rather than a direct effect. Therefore, the importance of sport participation in establishing adolescents' good sport values should be recognized, and the possibility of sport media as an agent of socialization leading to participation in sports should be acknowledged and leveraged.

\section{References}

[1] E. E. Snyder, and E. A. “Spretzer. Family influence and involvement in sports”. Research quarterly, 44(3), 243249 (1973) DOI: 10.1080/10671188.1973.10615203

[2] S. W. Lee, J. H. Lee, and T. H. Kim. "The Influence of the Media Sport Involvement Experience of Adolescence on Formation of Sport Star Image and Sports Participation”. Journal of Sport and Leisure Studies, 52(1), 225235 (2012)

[3] J. A. Yoo, S. H. Jun, and Y. S. Choi. “A curriculum development on inclusive physical education for integrated future society”. Journal of Learner-Centered Curriculum and Instruction. 17(12), 497-513 (2017)

[4] O. S. Lee. "Exploring the characterizations and needs of after-school physical activities for designing life skill development programs”. The Korean Journal of Physical Education, 54(1), 255-270 (2015)

[5] S. H. Hong. "The Criteria for Selecting Appropriate Fit Indices in Structural Equation Modeling and Their Rationales”. Korean Journal of Clinical Psychology, 19(1), 161-177 (2000) 
[6] Y. R. Kim. "The Study on the Relationship among Media Sport Contact, Sport Star Image, and Attitude to Sport”. Journal of Sport and Leisure Studies, 41, 323-333 (2010)

[7] C. K. Chung. "Media sports accommodation main point is participation level and relation of sports sense of values”. Doctor's thesis, Kookmin University, Seoul, Korea (2006)

[8] E. H. Evarett. “On the Theory of Social Change: How Economic Growth Begins”, Homewood, III. : Dorsey Press (1962)

[9] G. W. Allport, P. E. Vernon, and G. A. Lindsey. Study of Values, Boston: Houghton Mifflin (1960)

[10] H. Y. Jung. "The casual relationship among sports value, sports attitude, and sports participation according to involvement experience of sportsmedia of adolecents”. Docter's thesis, Yongin University, Gyeonggi, Korea (2008)

[11] J. P. Woo. “Concept and Understanding of Structural Equations”. Seoul: Hannarae Press (2015)

[12] Kline, R. B. “Principles and practice of structural equation modeling”(3nd ed.). New York: Guilford (2011)

[13] S. G. West, J. F. Finch, \& P. J. Curran. "Structural equation model with non-normal variables: Problems and remedies”. In R. Hoyle (Ed.), Structural Equation Modeling: Concepts, Issues and Applications. Newbury Park, CA: Sage (1995)

[14] T. J. Sung. Simple stat using SPSS/AMOS. Seoul: HakJisa Press (2014)

[15] W. M. Leonard. A sociological of sport. Mineapolis, MN: Burgess Publishing company (1980)

\section{Author}

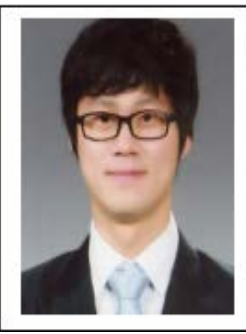

Seung-Man Lee

$\mathrm{PhD}$ in education

GeumHo High School (P.E.) Teacher

Global Cyber University adjunct professor 